\title{
Metais do Grupo da Platina: História, Propriedades e Aplicações
}

\author{
Fabrício Eugênio Alves ${ }^{a}$, Priscila Pereira Silva $^{\mathrm{b}}$ e Wendell Guerra ${ }^{\text {a* }}$
}

\begin{abstract}
O
s metais do grupo da platina constituem-se em seis elementos ( $R u, R h, P d$, Os, Ir e Pt) e as suas propriedades primorosas têm sido utilizadas para as mais variadas aplicações industriais, como por exemplo na produção de catalisadores e de fármacos. Considerando a importância e a aplicabilidade destes metais, este artigo descreve de forma sucinta a história, as propriedades e algumas das aplicações destes elementos.
\end{abstract}

Palavras chave

Metais do grupo da platina; platina; ruténio.

\section{INTRODUÇÃO}

O grupo da platina é um nome dado a seis elementos metálicos que possuem algumas propriedades físicas e químicas similares e que tendem a ocorrer juntos nos mesmos depósitos minerais. Estes metais, também conhecidos como platinóides, são o ruténio $(\mathrm{Ru})$, o ródio $(\mathrm{Rh})$, o paládio $(\mathrm{Pd})$, o ósmio (Os), o irídio (Ir) e a platina (Pt) [1]. Este grupo de elementos somados ao ferro, cobalto e níquel estão entre os nove elementos pertencentes à família oito da clássica tabela periódica construída por Mendeleev (actualmente grupos 8, 9 e 10 da tabela periódica). No entanto, as semelhanças horizontais existentes entre estes elementos são maiores que em qualquer outro conjunto (grupo) da tabela periódica, exceptuando-se os lantanídeos. Tais semelhanças, que são devidas principalmente a contracção lantanídica, enfatizou a classificação dos mesmos em dois grupos: o dos metais ferrosos ( $\mathrm{Fe}, \mathrm{Co}$ e $\mathrm{Ni}$ ) e o dos metais do grupo da platina.

a Instituto de Química, Universidade Federal de Uberlândia, Campus Santa Mônica, Bloco 1D 38400-902, Uberlândia - MG - Brasil

b Departamento de Química, Instituto de Ciências Exatas, Universidade Federal de Minas Gerais, Campus Pampulha, 31.270-901, Belo Horizonte - MG * e-mail: wg@iqufu.ufu.br
Todos os platinóides são classificados como metais de transição, estão localizados nos períodos 5 e 6 , grupos 8 , 9 e 10, no bloco $d$ da tabela periódica, Figura 1. São sólidos metálicos lustrosos à temperatura ambiente, formam ligas uns com os outros e possuem excelentes propriedades catalíticas. Além disso, são resistentes a ataques químicos, estáveis em altas temperaturas e possuem boas propriedades eléctricas. Em solução formam grande número de iões complexos e compostos de coordenação, incluindo ligantes como o monóxido de carbono, entre outros. Um destes complexos, o ião de Creutz-Taube, cuja fórmula estrutural é $\left[\left(\mathrm{NH}_{3}\right)_{5} \mathrm{Ru}(\mathrm{pz}) \mathrm{Ru}\left(\mathrm{NH}_{3}\right)_{5}\right]^{5+}$, possui dois átomos de ruténio em estados de oxidação diferentes, +2 e +3 , rodeados por moléculas de amoníaco unidos por uma molécula de m-pirazina (pz). Este complexo deu origem ao estudo de materiais de valência mista, que é hoje um campo bastante excitante da electrónica molecular.

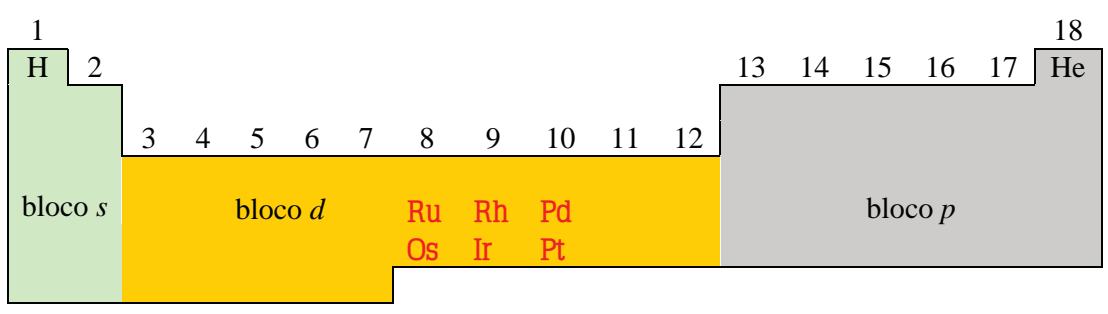

Figura 1 - Tabela Periódica. Em destaque os seis metais do grupo da platina
Os primorosos atributos dos metais do grupo da platina tem sido explorados para as mais variadas aplicações industriais e no caso da platina, alguns de seus compostos tem até mesmo sido utilizados na indústria farmacêutica $[2,3]$. De facto, os metais do grupo da platina são usados em pequenas quantidades em aplicações especializadas, como na síntese de compostos de alto valor acrescentado, seja como reagente ou como catalisador. Isto é um reflexo da escassez desses elementos aliada à grande procura, que gera um alto valor de mercado. Considerando a importância e aplicabilidade destes metais, este artigo descreve de forma sucinta a história, as propriedades e aplicações destes elementos.

\section{Ocorrência na Natureza}

Os metais do grupo da platina são bastante escassos na crosta terrestre e por isso apresentam elevado valor

18

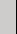


comercial. Como exemplo, a concentração de platina (abundância estimada) na crosta terrestre é de aproximadamente $5 \mathrm{ng} / \mathrm{kg}$, sendo que os demais metais do grupo são bem menos abundantes [3]. A maior parte dos metais do grupo da platina em circulação no mundo é oriunda de jazidas de minérios localizadas na África do Sul, Rússia, Estados Unidos e Canadá. No caso da platina, as minas da África do Sul fornecem hoje três quartos da produção mundial do metal. Quanto ao paládio, a maior parte do metal em circulação no mundo provém de jazidas de minérios localizadas na Rússia (principal produtor), apesar da África do Sul possuir a maior reserva. A platina e os demais metais do grupo tendem a ocorrer em pequenas quantidades associadas aos minérios de cobre e níquel, sendo recuperados através da refinação electrolítica dos principais metais do minério. Neste caso, ocorre a separação do metal presente em maior quantidade ( $\mathrm{Ni}, \mathrm{Cu}$ ) e a impureza (lodo anódico) é processada de modo a obter os metais do grupo da platina. As diferenças de reactividade e de solubilidade dos diversos compostos destes metais são utilizadas para separá-los [2].

Na forma combinada a platina é encontrada principalmente no mineral sperrilita $\left(\mathrm{PtAs}_{2}\right)$. É importante ressaltar que minerais de platina são também uma fonte de obtenção de paládio e outros metais do grupo, mas como dito anteriormente, estes são bem escassos. Os outros metais, $\mathrm{Ru}$, Os, Ir e Rh são encontrados em poucos minerais, principalmente na Rússia (Montes Urais) e nas Américas do Sul e do Norte, mas não são comercializáveis. Por exemplo, o ruténio é encontrado na laurita, $\mathrm{RuS}_{2}$, e em pequenas quantidades na pentlandita, $(\mathrm{Fe}, \mathrm{Ni})_{9} \mathrm{~S}_{8}[1]$.

\section{HISTÓRIA}

Devido ao facto dos metais do grupo da platina serem encontrados juntos na natureza, as histórias das suas descobertas estão interligadas. Mas antes de falar sobre a descoberta destes metais como elementos, é interessante comentar que estes metais nobres foram encontrados em objectos que datam de 700 a.C. Como exemplo tem-se o famoso caixão de Thebes (da antiga Grécia) que foi decorado com hieróglifos (sinais da escrita de antigas civilizações) em ouro, prata e uma liga contendo platina. Outro exemplo é uma liga de platina/ouro que foi encontrada em Esmeraldas (Equador) no início do século XX em objectos decorativos confeccionados por povos pré-colombianos [4]. Os demais metais do grupo também foram utilizados em joalharia pelos egípcios, pelos povos antigos do Peru, Equador e índios pré-colombianos [5]

Embora existam registos remotos do uso desses metais, os estudos e aplicações dos mesmos são mais recentes. De facto, os elementos do grupo da platina só conquistaram a atenção há cinco séculos quando mineiros e cientistas sentiram a necessidade de desenvolver métodos capazes de separar esses metais do ouro. A separação constituía um grande problema, uma vez que era difícil fazê-la devido às propriedades dos platinóides, tais como elevado ponto de fusão e grande resistência à corrosão.

As descobertas dos metais do grupo da platina como novos elementos ocorreram nos séculos XVI e XVII. O primeiro passo para a descoberta foi dado por conquistadores espanhóis que procuravam ouro nas Américas e o encontraram misturado com os metais do grupo da platina em quantidades variáveis. É conveniente destacar que em 1557 o cientista franco-italiano Júlio César Scaligero descreveu um metal refractário encontrado na América Central, que provavelmente se tratava da platina [4], contudo, o metal não foi estudado sistematicamente por Scaligero. A platina, cujo nome é devido à sua semelhança com o metal prata (platina é um diminutivo de plata, palavra espanhola para prata), foi descrita como substância elementar pelo espanhol Antonio de Ulloa em 1735. Ulloa, que era militar, naturalista e matemático, descobriu a platina nas minas do Rio Pinto e caracterizou-a como elemento em 1748 , enquanto os pesquisadores franceses consideravam-na uma liga [4]. A platina, o oitavo metal a ser descoberto, foi o primeiro elemento do grupo da platina a ser separado e identificado [3]. Durante muitos anos a platina não teve qualquer valor excepto como um meio de falsificação de outros metais nobres.

Sobre a história moderna de quatro outros platinóides, dois nomes merecem destaque. São eles os químicos ingleses Willian Hyde Wollaston e Smithson Tennant que por volta de 1800 formaram uma sociedade com o propósito de refinar a platina. Durante esse trabalho eles descobriram quatro outros metais desse grupo: paládio, ródio, irídio e ósmio. A purificação da platina consistia na adição de água régia quente ao mineral bruto, o que gerava uma solução e um precipitado negro. A platina solubilizava-se na água régia e a maior parte desse metal era removido como hexacloroplatinato de amónio, $\left(\mathrm{NH}_{4}\right)_{2}\left[\mathrm{PtCl}_{6}\right]$, que era formado pela adição de cloreto de amónio à solução de água régia [4].

Inicialmente, após a extracção da platina, o restante da solução e o resíduo insolúvel de coloração negra eram desprezados. Posteriormente, Wollaston ocupou-se do estudo da solução, enquanto Tennant investigou o precipitado negro. Wollaston descobriu dois metais presentes na parte solúvel: o paládio e o ródio. Tennant também descobriu dois outros metais na porção insolúvel: irídio e ósmio.

Após a extracção da platina com adição de $\mathrm{NH}_{4} \mathrm{Cl}$, era adicionado zinco à solução levando à precipitação de platina residual, paládio, ródio, cobre e chumbo. Os dois últimos eram facilmente removidos pela adição de ácido nítrico diluído ao precipitado. $\mathrm{O}$ resíduo, agora sem cobre e chumbo, era então redissolvido em água régia. A separação do paládio era feita pela neutralização dessa solução, seguida da adição de cianeto de mercúrio, o que gerava um precipitado amarelo, o cianeto de paládio, $\mathrm{Pd}(\mathrm{CN})_{2}$. Posteriormente, outros processos eram feitos até a obtenção do paládio puro. Alguns propõem que esse elemento recebeu esse nome graças ao asteróide Pallas, outros dizem que foi em homenagem à deusa grega da sabedoria cujo nome também é Pallas. Apesar de o paládio ter sido descoberto em 1802, o artigo que descreve a descoberta do elemento só foi oficialmente publicado em 1805 [5]. 
Logo após a descoberta do paládio, Wollaston verificou a existência do elemento ródio, que foi separado da solução pela adição do cloreto de sódio, que gerava o composto rosa $\mathrm{Na}_{3}\left[\mathrm{RhCl}_{6}\right] \cdot \mathrm{nH}_{2} \mathrm{O}$. Devido à coloração do composto formado, esse novo elemento recebeu o nome de ródio, do grego rhodon que significa rosa. Em 1804 Wollaston publicou um artigo sobre a descoberta do ródio [6].

Enquanto Wollaston estudou a parte solúvel, Tennant trabalhou com o resíduo negro da dissolução da platina bruta em água régia e descobriu em 1804 dois metais. Ele aqueceu esse sólido com hidróxido de sódio, dissolveu o resíduo em água obtendo um novo precipitado e uma solução que provavelmente continha os compostos cis- $\left[\mathrm{Os}(\mathrm{OH})_{2} \mathrm{O}_{4}\right]$ e $\mathrm{OsO}_{4}$. O tetróxido de ósmio, $\mathrm{OsO}_{4}$, é um sólido tóxico, volátil de odor penetrante. Esse elemento recebeu o nome de ósmio, do grego osme, que significa cheiro, por causa do odor característico gerado durante a separação desse metal [7]. O resíduo insolúvel em água foi tratado com ácido clorídrico, gerando cristais vermelhos escuros. Provavelmente tratava-se de $\mathrm{Na}_{2}\left[\mathrm{IrCl}_{6}\right] \cdot \mathrm{nH}_{2} \mathrm{O}$. $\mathrm{O}$ novo metal recebeu o nome de irídio devido à impressionante variedade de cores que eram geradas enquanto o sólido era dissolvido em $\mathrm{HCl}$ e em homenagem a Íris, deusa grega do arco-íris [8]. O nome irídio é derivado da palavra latina Iris que significa colorido.

Além dessas quatro descobertas, Wollaston e Tennant desenvolveram o processo para produção de platina maleável para substituir o ouro em algumas aplicações onde era indispensável a presença de um metal inerte. A produção da platina maleável gerou grande lucro para os ingleses. É importante ressaltar que a participação de Tennant nessa produção foi quase exclusivamente de ordem financeira. Além dos metais descobertos por Wollaston e Tennannt existia no mineral bruto de platina outro metal, o ruténio, que era insolúvel em água régia, assim como o ósmio e o irídio, mas que não foi identificado pelos químicos ingleses. O ruténio só foi oficialmente descoberto em 1844 pelo químico russo Karl Karlovith Klaus enquanto ele analisava resíduos de platina. Klaus concluiu que no resíduo do mineral de platina que ele trabalhava havia $10 \%$ de platina e uma pequena fracção dos seguintes metais: irídio, ósmio e paládio. Além desses também estava presente no resíduo um novo composto. Ele relatou os resultados das suas experiência a Kankrin, ministro das finanças da Rússia, e ofereceu-se para extrair a platina do resíduo. Como a platina era de grande interesse económico, Klaus ganhou o apoio financeiro que precisava para prosseguir as suas pesquisas e ainda recebeu $8 \mathrm{~kg}$ de resíduo, com a condição de que, após um ano, ele devolvesse os metais extraídos e relatasse os resultados de seus trabalhos. Klaus trabaIhou arduamente até que descobriu um método para extrair o ruténio. 0 método consistia na precipitação do cloreto de ruténio, seguido do tratamento com sulfureto de hidrogénio, obtendo-se então um composto denso com cor de safira. Nenhum outro platinóide formava compostos semeIhantes, o que mostrava tratar-se de um novo elemento. Klaus conseguiu obter $6 \mathrm{~g}$ do ruténio puro. O nome ruténio origina da palavra latina ruthenia que significa Rússia [9, 10].

Klaus pode ser considerado o criador da química dos metais do grupo da platina, pois ele realizou uma ampla investigação dos platinóides, descreveu um método de separação dos seis metais do grupo de forma pura e descobriu as semelhanças e diferenças entre os elementos em tríades: ruténio-ródio-paládio e ósmio-irídioplatina, proporcionando assim uma justificativa para Mendeleev incluir todos os seis metais no grupo VIII do sistema periódico [10].

\section{Algumas Propriedades dos Metals do Grupo da Platina}

Algumas propriedades atómicas e físicas referentes aos metais do grupo da platina encontram-se na Tabela 1.

\section{1) Platina:}

É um metal branco-cinza, de estrutura cúbica compacta, brilhante, não muito duro, que pode ser trabalhado e soldado a quente. Quando combinada exibe vários estados de oxidação que vão de 0 a +6 embora os estados
+2 e +4 sejam os mais comuns. Por ser um metal pouco reactivo (de difícil oxidação) não reage com os ácidos clorídrico $(\mathrm{HCl})$ e nítrico $\left(\mathrm{HNO}_{3}\right)$ mas é atacada pela mistura de ambos (água régia), formando o ácido hexacloroplatínico, $\mathrm{H}_{2}\left[\mathrm{PtCl}_{6}\right]$. Com flúor e oxigénio reage a elevadas temperaturas gerando $\mathrm{PtF}_{6}$ e $\mathrm{PtO}_{3}$, respectivamente. Estes são os únicos compostos conhecidos onde a platina está no estado de oxidação +6 . Apesar de pouco reactiva, os seus iões no estado de oxidação +2 e +4 formam um número extremamente elevado de complexos (compostos complexos ou de coordenação) [11-14].

\section{2) Paládio:}

É um metal que possui coloração branco prateado, estrutura cúbica compacta e elemento considerado denso $\left(\mathrm{d}=12.26 \mathrm{~g} \mathrm{~cm}^{-3}\right)$, embora seja o de menor densidade quando comparado aos demais elementos do grupo da platina. Assim como a platina, este metal amolece antes de fundir, podendo ser trabalhado e soldado. É pouco reactivo e bastante resistente à corrosão. Dissolve-se em ácidos oxidantes, bases fundidas e em água régia $(\mathrm{HCl} /$ $\mathrm{HNO}_{3}$ ) gerando o ácido $\mathrm{H}_{2}\left[\mathrm{PdCl}_{4}\right]$. Quando combinado, o paládio exibe os estados de oxidação $0,+1,+2$ e +4 embora o estado +2 seja o estável. O estado de oxidação +4 é instável e é atingido quando combinado com o flúor $\left(\mathrm{PdF}_{4}\right)$ e oxigénio $\left(\mathrm{PdO}_{2}\right)$ podendo também ocorrer em alguns complexos. O estado de oxidação +2 ocorre no ião hidratado $\left[\mathrm{Pd}\left(\mathrm{H}_{2} \mathrm{O}\right)_{4}\right]^{2+} \mathrm{e}$ num número extremamente elevado de complexos (compostos complexos ou de coordenação) [11-14].

\section{3) Ruténio:}

É um metal branco prateado, brilhante, muito duro e tão quebradiço que pode ser pulverizado com facilidade. Cristaliza com estrutura compacta hexagonal. Quimicamente não é atacado por ácidos, nem mesmo por água régia. No entanto, é solúvel em álcalis fundidos e em presença de clorato de potássio, onde o ruténio é energeticamente oxidado. Reage com oxigénio e halogéneos a altas temperaturas. Os estados de oxidação mais comuns são +2 , +3 e +4 , sendo o estado trivalente o mais estável. Outros estados de oxidação encontrados em compostos 
são $+5,+7$ e +8 . O tetraóxido de ruténio, RuO4 (estado de oxidação +8 ), é muito oxidante, mais que o análogo ósmio, e decompõe-se violentamente a altas temperaturas. O ruténio é um metal versátil que pode facilmente formar ligações carbono-ruténio, formando compostos organometálicos que são vastamente aplicados em catálise [12-14].

\section{4) Ródio:}

É um metal duro de coloração branco prateado, cristaliza com estrutura compacta cúbica. Este platinóide é tripositivo na grande maioria de seus compostos, embora eventualmente ocorra nos estados de valência $+1,+2,+4$ e +6. $O$ ródio compacto é completamente insolúvel em todos os ácidos, inclusive em água régia. Entretanto, o negro de ródio, produzido por redução de sais de ródio $(\mathrm{VI})$ com formato de amónia, é solúvel em água régia, em ácido sulfúrico concentrado a quente e em ácido clorídrico na presença de ar [12-14].

\section{5) Ósmio:}

É um metal branco-azulado, muito duro e quebradiço. É o mais denso dos elementos conhecidos. Dentre os metais platínicos, é o que possui ponto de fusão mais alto $\left(3033^{\circ} \mathrm{C}\right)$. Assim como o ruténio, cristaliza com estrutura hexagonal. É capaz de assumir um grande número de estados de valência que vão desde +1 até +8 , sendo o estado de valência tetravalente o mais estável. O ósmio não é atacado por ácidos não oxidantes, mas quando pulverizado é atacado por ácido nítrico e pelo ácido sulfúrico concentrado a quente [12-14].

\section{6) Irídio:}

É um metal branco prateado, muito duro, bastante quebradiço. É entre os elementos conhecidos até ao momento o que apresenta maior densidade (22.65 $\left.\mathrm{g} \mathrm{cm}^{-3}\right)$ e maior resistência à corrosão. Cristaliza com estrutura compacta cúbica. $\mathrm{O}$ estado de valência +3 é o mais comum, mas o elemento apresenta os estados $+1,+2$, +4 e +6 . O irídio não é atacado pelos ácidos usuais, inclusive a água régia. É, entretanto, atacado pelo ácido clorídrico em presença de ar, se aquecido sob pressão a $125^{\circ} \mathrm{C}$. Os álcalis fundidos não têm acção sobre o metal [12-14].

Tabela 1 - Algumas propriedades atómicas e físicas para os metais do grupo da platina

\begin{tabular}{|c|c|}
\hline \multicolumn{2}{|r|}{ Platina } \\
\hline Número atómico & $Z=78$ \\
\hline Massa molar & $M=195.08 \mathrm{~g} \mathrm{~mol}^{-1}$ \\
\hline Ponto de fusão & $\mathrm{T}_{f}=1769^{\circ} \mathrm{C}$ \\
\hline Isótopos naturais & $\begin{array}{l}{ }^{190} \mathrm{Pt}(0.01 \%),{ }^{192} \mathrm{Pt}(0.78 \%),{ }^{194} \mathrm{Pt}(32.97 \%) \\
{ }^{195} \mathrm{Pt}(33.83 \%),{ }^{196} \mathrm{Pt}(25.24 \%) \text { e }{ }^{198} \mathrm{Pt}(7.16 \%)\end{array}$ \\
\hline \multicolumn{2}{|r|}{ Paládio } \\
\hline Número atómico & $Z=46$ \\
\hline Massa molar & $M=106.42 \mathrm{~g} \mathrm{~mol}^{-1}$ \\
\hline Ponto de fusão & $\mathrm{T}_{f}=1554^{\circ} \mathrm{C}$ \\
\hline Isótopos naturais & $\begin{array}{l}{ }^{102} \mathrm{Pd}(1.02 \%),{ }^{104} \mathrm{Pd}(11.14 \%),{ }^{105} \mathrm{Pd}(22.33 \%) \\
{ }^{106} \mathrm{Pd}(27.33 \%),{ }^{108} \mathrm{Pd}(26.46 \%) \text { e e }{ }^{110} \mathrm{Pd}(11.72 \%)\end{array}$ \\
\hline \multicolumn{2}{|r|}{ Ruténio } \\
\hline Número atómico & $Z=44$ \\
\hline Massa molar & $M=101.07 \mathrm{~g} \mathrm{~mol}^{-1}$ \\
\hline Ponto de fusão & $\mathrm{T}_{f}=2334^{\circ} \mathrm{C}$ \\
\hline Isótopos naturais & $\begin{array}{l}{ }^{96} \mathrm{Ru}(5.52 \%),{ }^{98} \mathrm{Ru}(1.88 \%),{ }^{99} \mathrm{Ru}(12.70 \%) \\
{ }^{100} \mathrm{Ru}(12.60 \%),{ }^{101} \mathrm{Ru}(17.00 \%),{ }^{102} \mathrm{Ru}(31.60 \%) \mathrm{e} \\
{ }^{104} \mathrm{Ru}(18.7 \%)\end{array}$ \\
\hline \multicolumn{2}{|r|}{ Ródio } \\
\hline Número atómico & $Z=45$ \\
\hline Massa molar & $M=102.90 \mathrm{~g} \mathrm{~mol}^{-1}$ \\
\hline Ponto de fusão & $T_{f}=1964{ }^{\circ} \mathrm{C}$ \\
\hline Isótopos naturais & ${ }^{103} \mathrm{Rh}(100 \%)$ \\
\hline \multicolumn{2}{|r|}{ Ósmio } \\
\hline Número atómico & $Z=76$ \\
\hline Massa molar & $M=190.23 \mathrm{~g} \mathrm{~mol}^{-1}$ \\
\hline Ponto de fusão & $T_{f}=3033{ }^{\circ} \mathrm{C}$ \\
\hline Isótopos naturais & $\begin{array}{l}{ }^{184} \mathrm{Os}(0.02 \%),{ }^{186} \mathrm{Os}(1.59 \%),{ }^{187} \mathrm{Os}(1.96 \%) \\
{ }^{188} \mathrm{Os}(13.24 \%),{ }^{189} \mathrm{Os}(16.15 \%),{ }^{190} \mathrm{Os}(26.26 \%) \mathrm{e} \\
{ }^{192} \mathrm{Os}(40.78 \%)\end{array}$ \\
\hline \multicolumn{2}{|r|}{ Irídio } \\
\hline Número atómico & $Z=77$ \\
\hline Massa molar & $M=192.21 \mathrm{~g} \mathrm{~mol}^{-1}$ \\
\hline Ponto de fusão & $\mathrm{T}_{f}=2466^{\circ} \mathrm{C}$ \\
\hline Isótopos naturais & ${ }^{191} \operatorname{Ir}(37.3 \%),{ }^{193} \operatorname{Ir}(62.7 \%)$ \\
\hline
\end{tabular}

Dados retirados das referências [1, 3].

\section{APLICAÇÕES Platina e Paládio}

A maior parte da platina e do paládio produzidos no mundo são utilizados na produção de catalisadores para escapes de veículos automóveis. O restante é utilizado na produção de jóias, na indústria petroquímica, na indústria electrónica, na odontologia, entre outras aplicações [1, 3]. O uso do paládio e da platina nestes sectores da indústria pode ser explicado pelo facto destes elementos serem muito resistentes à corrosão, mesmo a altas temperaturas, além de serem bastante dúcteis e maleáveis. Devido ao alto custo do paládio, a indústria tem procurado substituir o metal pelo níquel que é mais barato.

No que se refere à produção de catalisadores, os elementos são utilizados há muito tempo em conversores catalíticos que reduzem a poluição emitida por automóveis. Estes catalisadores convertem os gases nocivos $\mathrm{CO}$, NO, 
$\mathrm{NO}_{2}$ e hidrocarbonetos, presentes nos gases de escape de automóveis, nos compostos $\mathrm{CO}_{2}$ e $\mathrm{N}_{2}$ que são naturalmente encontrados na atmosfera [2]. O paládio é usado como catalisador na produção de etanal, processo Wacker (que não é mais o principal processo industrial), reacções de hidrogenação e nas reacções de acoplamento carbono-carbono [2]. Também é utilizado na obtenção do ácido nítrico e do ácido tereftálico $\left(\mathrm{C}_{8} \mathrm{H}_{6} \mathrm{O}_{4}\right)$ purificado que é usado na fabricação de fibras artificiais. Especula-se que conversores catalíticos de platina possam ser utilizados na obtenção do hidrogénio como combustível [11].

Quanto à utilidade destes metais na medicina, um complexo muito importante de platina é o cis[(diaminodicloro) platina(II)], $\quad \operatorname{cis}\left[\mathrm{Pt}\left(\mathrm{NH}_{3}\right)_{2} \mathrm{Cl}_{2}\right]$, comummente chamado de "cisplatina". A cisplatina é actualmente muito utilizada contra o cancro do testículo e do ovário onde se obtém até $90 \%$ de hipótese de cura. Outros cinco complexos (Figura 2) são também utilizados, porém são menos eficientes apesar de serem menos tóxicos [11]. Devido ao sucesso da aplicação destes compostos como anti-cancerígenos, muita pesquisa foi desenvolvida nesta área. Vários complexos de platina e de outros metais, especialmente os metais do grupo da platina, foram e estão sendo sintetizados e estudados como agentes anti-tumorais. Pode-se dizer que a cisplatina foi o composto precursor de uma nova área de pesquisa na química, denominada Química Inorgânica Medicinal.

Devido à sua semelhança química com a platina, alguns complexos de paládio têm sido estudados visando a obtenção de fármacos. Também existem compostos de paládio que possuem boa actividade anti-tumoral e, além disso, são promissores agentes anti-infecciosos. No entanto, apesar das pesquisas intensas, estes não são ainda utilizados nas práticas médicas. Todavia, o isótopo radioactivo de ${ }^{103} \mathrm{Pd}$ é utilizado no tratamento do cancro da próstata em estado avançado [15].

No que se refere a outras aplicações, são utilizadas ligas contendo platina em odontologia protética para implan-
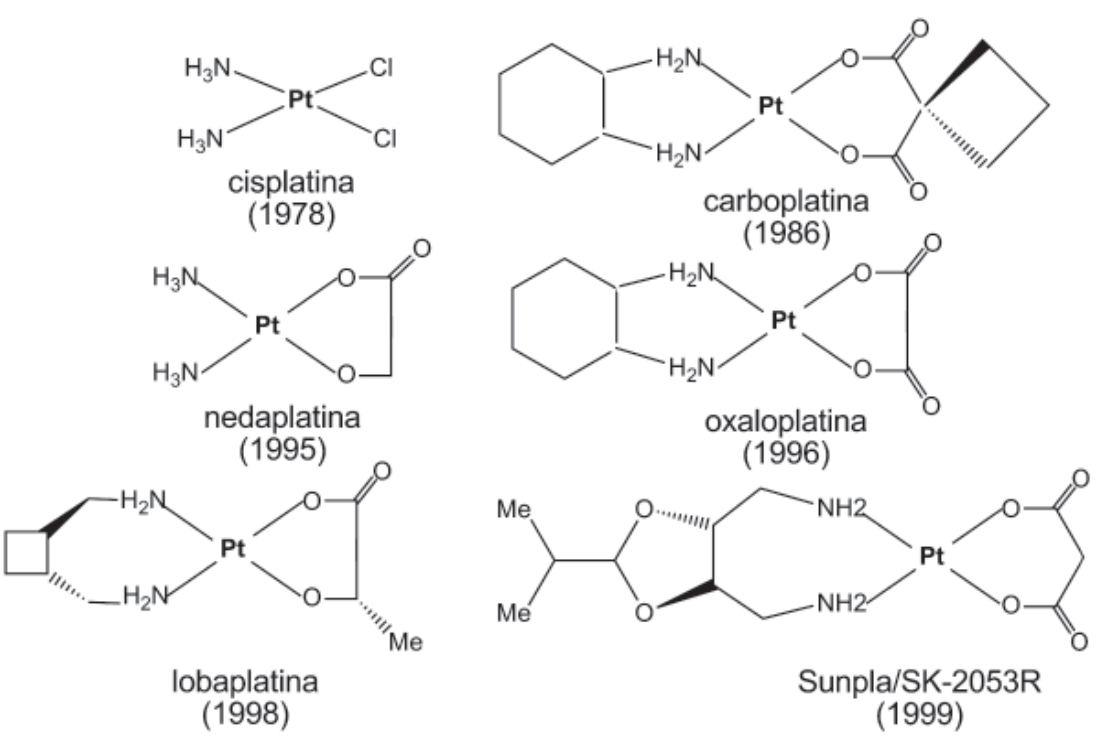

Figura 2 - Complexos de platina utilizados em clínica médica (entre parênteses o ano de introdução nas práticas clínicas). Os complexos denominados cisplatina, carboplatina e oxaloplatina são utilizados em todos os países do mundo

tes e fixação de brocas e em outras situações onde se necessita de materiais resistentes à corrosão e à temperatura elevada. O composto intermetálico $\mathrm{Cr}_{3} \mathrm{Pt}$ (uma liga homogénea com composição definida) é utilizado para revestir navalhas conferindo uma maior dureza, permitindo que a lâmina fique afiada por mais tempo [11].

$\mathrm{Na}$ indústria electrónica, o paládio é utilizado na produção de componentes eléctricos para telefones móveis, aparelhos de fax, computadores portáteis e televisores LCD. Também é utilizado em revestimentos para conectores e na produção de circuitos híbridos integrados [1, 3]. Na forma metálica, o paládio adsorve hidrogénio gasoso e quando aquecido ao rubro pode adsorver um volume de hidrogénio superior a 900 vezes o seu volume. É o metal que adsorve a maior quantidade de hidrogénio e, por isso, é utilizado na purificação desse gás. Já o composto $\mathrm{PdCl}_{2}$ adsorve monóxido de carbono e é usado em detectores para esse gás [1].

\section{Ruténio e Ródio}

Devido à sua capacidade de endurecer platina e paládio, o ruténio é adicionado em ligas contendo esses elementos com a finalidade de tornálas resistentes ao desgaste. Também é acrescentado um pouco de ruténio, cerca de $0.1 \%$, à liga de titânio para melhorar a resistência da mesma à corrosão. Além disso, o ruténio é usado juntamente com o molibdénio na confecção de uma liga supercondutora a $10.6 \mathrm{~K}$. Este metal também é usado em algumas peças de joalharia, na forma de liga com ouro. Este platinóide é também usado como catalisador. Por exemplo, $\mathrm{O} \mathrm{RuO}_{2}$ é usado para remoção do sulfureto de hidrogénio em refinarias de petróleo e em outros processos industriais [1].

A importância de compostos de coordenação de ruténio têm crescido muito devido a diversas aplicações como catalisadores [14], sensibilizadores nos processos de degradação fotocatalítica de compostos orgânicos [16], sensibilizadores em células solares [17], entre outros. Além disso, assim como a platina e o paládio, os complexos de ruténio têm sido extensivamente avaliados como potenciais agentes anti-tumorais. Os primeiros compostos de ruténio testados como agentes anti-cancerígenos foram desenvolvidos por $M$. Clarke no início dos anos 80 [18]. Desde então, metalodrogas de ruténio têm sido objecto de intensos estudos quimioterapêuti$\cos [19,20]$.

As estruturas I e II, Figura 3, mostram dois complexos de ruténio promissores. O complexo II encontra-se em fase de testes clínicos e exibe alta actividade em tumores sólidos de cancro de cólon [21]. 


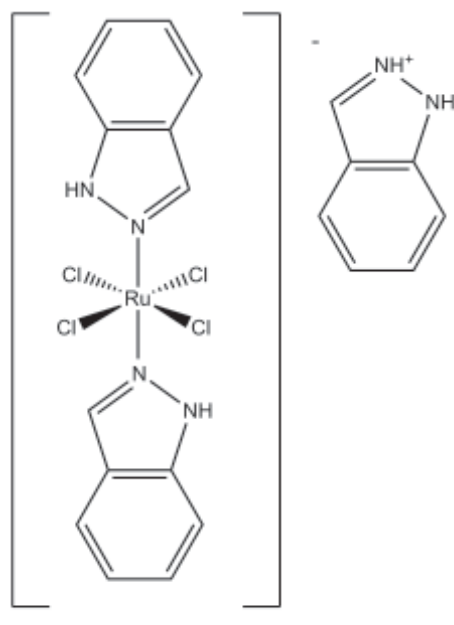

I

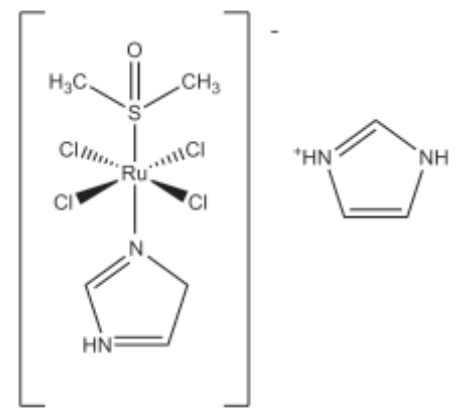

II

Figura 3 - Complexos de ruténio com significativa actividade anti-tumora

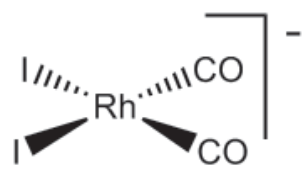

Figura 4 - Catalisador utilizado no processo Monsanto
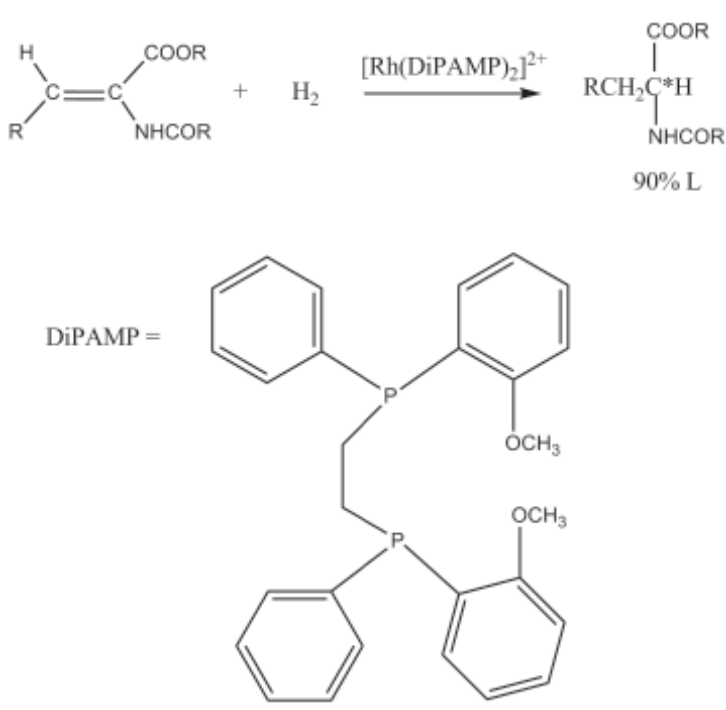

Figura 5 - Esquema para a hidrogenação assimétrica de alcenos pró-quirais

O ródio é de longe o metal mais caro do grupo da platina, pois ele é muito usado em processos catalíticos industriais e nos conversores catalíticos de automóveis, em conjunto com a platina e o paládio. Este metal é cerca de quarenta vezes mais caro do que o paládio, que tem uma aplicação catalítica muito menor, mesmo embora eles ocorram com abundância similar na crosta terrestre [13, 14].
Entre os compostos de ródio, os carboxilatos de ródio(II) são bem estudados, devido às suas propriedades anti-tumorais [22, 23]. Entretanto, o ródio é estudado em outras aplicações, tais como sensores electroquímicos e catálise química.

Um dos sistemas catalíticos mais explorados é o complexo de $\mathrm{Rh}(\mathrm{I})$, $\left[\mathrm{RhCl}\left(\mathrm{Ph}_{3}\right)_{3}\right]$, frequentemente chama- do de catalisador de Wilkinson. Este importante catalisador hidrogena uma ampla variedade de alcenos e alcinos $[13,14]$. Os complexos organometálicos de ródio são os mais enantioselectivos, sendo vastamente usados em sínteses orgânicas [23]. Um exemplo moderno do uso do ródio como catalisador é o processo Monsanto, onde o composto de ródio, Figura 4, catalisa a reacção de adição de monóxido de carbono a metanol gerando ácido acético. Outros exemplos são a hidroformilação, na qual a reacção entre monóxido de carbono e hidrogénio molecular com um alceno leva à produção de aldeído e à hidrogenação assimétrica de alcenos pró-quirais, Figura 5 $[2,14]$. Além disso, os compostos de ródio constituem-se numa alternativa promissora na produção de sensores electroquímicos, em função da grande possibilidade de variação das suas propriedades de transferência de electrões e de modulação dos potenciais redox via variação dos ligantes [24]. Também é importante destacar que a interacção dos complexos de ródio com proteínas, especialmente com enzimas, possibilita o aperfeiçoamento de biossensores já existentes [24]. Embora o ródio tenha boas aplicações apresenta como grande desvantagem o seu alto custo.

\section{Ósmio E IRÍDIO}

Entre os metais do grupo da platina, o irídio e o ósmio são os que possuem menor número de aplicações. Isto porque o irídio é o metal mais inerte do grupo e o ósmio é o mais tóxico.

No caso do irídio, o metal pode ser utilizado na produção de dispositivos que devem possuir elevado ponto de fusão, como cadinhos [1,13]. Algumas das suas ligas, como a de Pt/Ir são utilizadas em sistemas automóveis para aumentar a vida útil de eléctrodos de velas de ignição, que possuem alto valor de mercado e são amplamente usadas em helicópteros [13, 25]. O irídio, juntamente com o ósmio, é utilizado na produção de uma liga muito dura para a fabricação de diversos tipos de agulhas que podem ser utilizadas em gira-discos, bússolas e na ponta de canetas tinteiro. O seu isótopo ${ }^{192}$ Ir é usadoo na obtenção de radiografias [25]. 
Para o ósmio, além das aplicações citadas acima, na forma combinada com outros elementos, tem sido utilizado na produção de ligas com alta resistência mecânica. Em implantes cirúrgicos, é largamente utilizada uma liga de Os/Pt em válvulas artificiais para os pulmões e em marca-passos [1, 25]. Soluções de $\mathrm{OsO}_{4}$ são usadas como corantes biológicos em técnicas biomédicas para detecções microscópicas de impressões digitais, pois a matéria orgânica reduz o $\mathrm{OsO}_{4} \mathrm{a} \mathrm{OsO}_{2}$ que possui cor preta. $\mathrm{O} \mathrm{OsO}_{4}$, por ser um potente agente oxidante, é utilizado em química orgânica como catalisador na quebra de ligações duplas para a produção de cis-glicóis [13].

\section{Considerações Finais}

Embora o uso de metais do grupo da platina seja antigo, principalmente da platina, que pode ocorrer na natureza no estado nativo, o interesse nos estudos envolvendo a aplicabilidade destes metais é bem recente se comparada aos metais descobertos por civilizações antigas ( $\mathrm{Cu}, \mathrm{Au}, \mathrm{Ag}$ e $\mathrm{Pb}$ ). Um factor que contribui para uma maior restrição no uso destes metais é o seu alto valor de mercado, que é resultado da escassez na crosta terrestre e da complexidade envolvida nos processos de extracção e purificação desses elementos. Mesmo assim, tem aumentado a procura destes metais para as mais variadas aplicações, sendo actualmente utilizados principalmente na produção de catalisadores (Pt, Pd e Rh), ligas metálicas, jóias e fármacos $(\mathrm{Pt})$.

Quanto às perspectivas futuras da aplicação dos platinóides, podemos dizer que a utilização destes metais como catalisadores tem evoluído no sentido de reduzir as emissões nocivas ao meio ambiente provenientes de automóveis. Espera-se também que compostos de ruténio sejam usados no tratamento do cancro, pois além de apresentarem boa actividade antitumoral, possuem baixa toxicidade, quando comparados aos compostos de platina que actualmente são usados nas práticas médicas. Essa baixa toxicidade é devida à capacidade do ruténio de imitar a ligação do ferro com biomoléculas. Sendo assim, o Ru explora os mecanismos de defesa do organismo que seriam para a eliminação do ferro em excesso [26].

Para suprir a crescente procura mundial dos metais do grupo da platina e propiciar novas aplicações para estes elementos, faz-se necessária a descoberta de novas reservas minerais. O Brasil, que é um grande detentor de recursos minerais tem realizado pesquisas geológicas no sentido de encontrar reservas exploráveis destes metais, mas até o momento o país não produz em quantidades significativas metais do grupo da platina [11]. Outro factor relevante é a necessidade de reciclagem dos metais desse grupo e o uso consciente, pois além de escassos, eles possuem elevados custos.

\section{Agradecimentos}

À Universidade Federal de Uberlândia e à Universidade Federal de Minas Gerais.

\section{REFERÊNCIAS}

[1] SDBS Web: http://www.webelements. com (WebElements: the periodic table on the web, acedido em 06-04-2010).

[2] C. J. Jones, A química dos elementos dos blocos $d$ e $f$, Editora Bookman, Porto Alegre, 2002.

[3] SDBS Web: http://www.eoearth.org/ article/platinum (The encyclopedia of earth, acedido em 05-02-2010).

[4] J. H. Maar, História da Química, Editora Conceito, Florianópolis, 2008.

[5] Donald McDonald, Leslie B. Hunt, A History of Platinum and its Allied Metals, Johnson Matthey, London, 1982.

[6] SDBS Web: http://www.chemeddl. org/collections/ptl/PTL/elements/Pt/ frames.html (Periodic Table Live, acedido em 17-02-2010).
[7] W. P. Griffith; Platinum Metals Rev. 47 (2003)175-183.

[8] Ian E. Cottington, Johnson Matthey, Hatton Garden, Platinum Metals Rev.35 (1991) 141-151 e www.rsc. org/chemistryworld/podcast//ridium. asp, acedido em 17/01/2010

[9] W. P. Griffith, Platinum Metals Rev. 49 (2004)182-189.

[10] V. N. Pitchkov, Platinum Metals Rev. 40 (1996)181-188.

[11] P. P Silva, W. Guerra, Química Nova na Escola, 2 (2010) 128-129.

[12] Ohlweiler, Otto Alcides, Química Inorgânica, São Paulo, 1971.

[13] J. D. Lee, Química Inorgânica não tão Concisa, Editora Edgard Blücher, São Paulo, 1999.

[14] D. F. Shriver, P. W. Atkins, Química inorgânica, Editora Bookman, Porto Alegre, 2003.

[15] A. Garoufis, S. K. Hadjikakou, N. Hadjiliadis, Coord. Chem. Rev. 253 (2009) 1384-1397.

[16] A. K. M. Fung, B. K. W. Chiu, M. H. W. Lam, Water Res. 37 (2003)19391947.

[17] I. Bedja, P. V. Kamat, X. Hua, A. G. Lappin, S. Hotschandani, Langmuir 13 (1997) 2398-2403.

[18] M.J. Clarke, Met. Ions Biol. Syst. 11 (1980) 231-283

[19] M. A. Jakupec, E. Reisner, J. Med. Chem. 48 (2005) 2831-2837.

[20] R. E.Morris, R. E. Aird, J. Med. Chem. 44 (2001) 3616-3621.

[21] Z. ChengHe, G. LinLing, Z. YiYi, Z. FeiFei, W. GuangZhou, J. Lei, G. RongXia, Sci China Ser B-Chem. 52 (2009) 415-458.

[22] Najjar, R.; Quím. Nova 15 (1992) 323327 e A. R. Souza, R. Najjar, E. Oliveira, S. B. Zyngier, Meta-Based Drugs. 4 (1997) 39-41.

[23] E. S. C. Temba, I. M. F. Oliveira; C. L. Donnici, Quim. Nova 26 (2003) 112122.

[24] E. S. Gil e L. T. kubota, Quim. Nova 21(1998) 755-760.

[25] SDBS Web: http://environmentalchemistry.com/yogi/periodic/lr.html (Environmental Chemistry, acedido em 03-04-2010).

[26] C. S. Allardyce, P. J. Dyson, Platinum Metals Rev 45 (2001) 62-69.

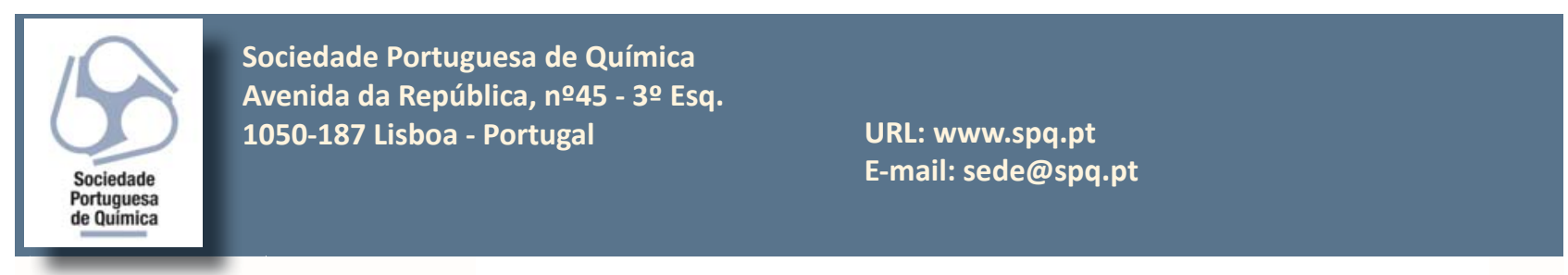




\section{Zas Jornadas de \\ Electroquímica e Inovação

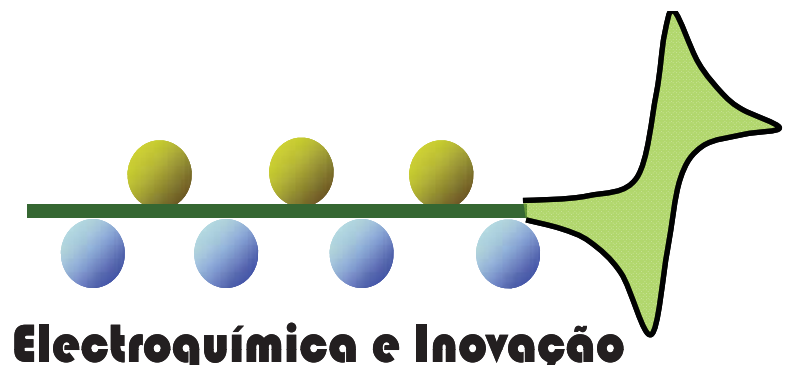

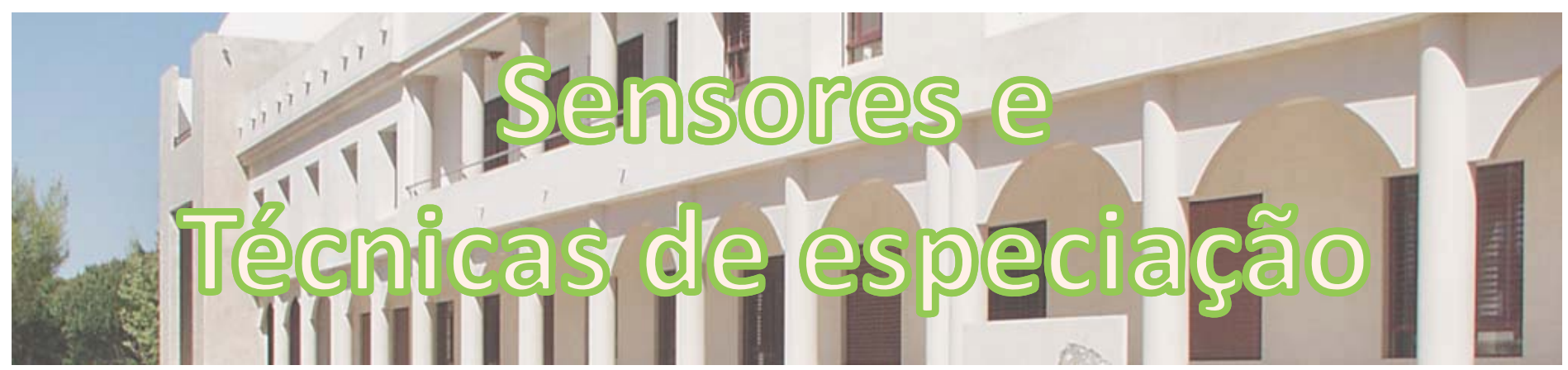

$\checkmark$ Palestrantes

Herman van Leeuwen - Wageningen University

Josep Galceran - Universitat de Lleida

Hubert Girault - École Polytechnique Fédérale de Lausanne

$\checkmark$ Datas importantes

Envio de resumo - 3 de Janeiro

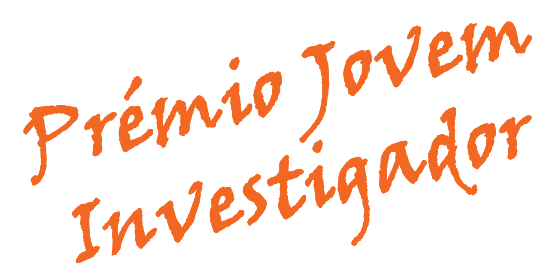

Inscrição - 21 de Janeiro

www.e-inov.org

Universidade do Algarve, Campus de Gambelas, Faro

11 de Fevereiro de 2011 